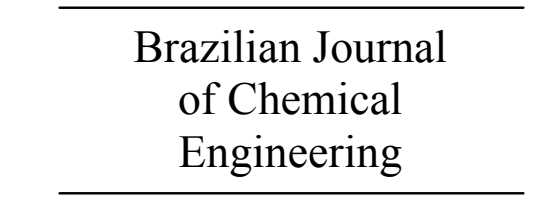

Vol. 21, No. 02 pp. 239 - 245, April - June 2004

\title{
SORPTION OF OIL POLLUTION BY ORGANOCLAYS AND A COAL/MINERAL COMPLEX
}

\author{
M.M.G. Ramos Vianna ${ }^{1}$, J.H.R. Franco ${ }^{2}$, C.A. Pinto ${ }^{3}$, \\ F.R. Valenzuela Díaz and P.M. Büchler ${ }^{5}$ \\ ${ }^{1}$ Department of Chemical Engineering, Polytechnic School, University of São Paulo, Phone +(55) (11) 5184-0150, \\ Fax +(55) (11) 3091-2275, São Paulo - SP, Brazil. E-mail: marilda.vianna@poli.usp.br \\ ${ }^{2}$ Department of Chemical Engineering, Polytechnic School, University of São Paulo, Phone +(55) (11) 3091-2275, \\ Fax+(55) (11) 3091-2275, São Paulo - SP, Brazil. E-mail: herneybr@yahoo.com. \\ ${ }^{3}$ Department of Chemical Engineering, Polytechnic School, University of São Paulo, Phone +(55) (11) 6693-2053, \\ Fax +(55) (11) 3091-2275, São Paulo - SP, Brazil. E-mail: capinto@usp.br \\ ${ }^{4}$ Department of Mettalurgical and Materials Engineering, Polytechnic School, University of São Paulo, (PMT/EPUSP), \\ Phone +(55) (11) 3091-2279, Fax +(55) (11) 3091-2275, São Paulo - SP, Brazil. E-mail: frrvdiaz@usp.br \\ ${ }^{5}$ Department of Chemical Engineering, Polytechnic School, University of São Paulo, Phone +(55) (11) 3091-2225, \\ Fax+(55) (11) 3091-2275, São Paulo - SP, Brazil. E-mail: pbuchler@usp.br
}

(Received: February 13, 2003 ; Accepted: January 9, 2004)

\begin{abstract}
Recently, increasing concern about pollution of groundwater by organic chemicals has led to research on the use of various adsorbents. This study addressed the sorption of phenol and organic compounds by two organoclays and a coal/mineral complex (ARO). The organoclays used were a bentonite from Brazil (SVC) and Wyoming bentonite (SWy) with quaternary ammonium salt (ABDMA). Swelling capacity of the sorbents in toluene, diesel, gas, Varsol and kerosene were measured. Absorption of organic compounds served as an ASTM D 281-95 base, which resulted in the following order for ABDMA-SVC: gas > toluene > kerosene $>$ diesel $>$ Varsol. ABDMA-SWy absorbed in the following order: gas $>$ toluene $>$ Varsol $>$ diesel $>$ kerosene. ARO absorbed: gas $>$ toluene $>$ diesel $>$ Varsol $>$ kerosene. Sorption of phenol followed the order of ABDMA-SVC $>$ ABDMA-SWy $>$ ARO. The adsorption data show that the materials prepared were effective in sorbing phenol, and that the Brazilian clay was the most efficient of the three materials.

Keywords: adsorption, sorption, absorption, organoclay, hydrocarbon, phenol.
\end{abstract}

\section{INTRODUCTION}

Soil and water contamination by hydrocarbons from leaking storage tanks and improper disposal of hazardous wastes are of concern worldwide. Petroleum hydrocarbons are responsible for $65 \%$ of all contaminated groundwater sites (EPA/540/R95/508b). Treatment of petroleum contaminated sites is a subject of almost unlimited scope. Sites can be as simple as a corner service station with little contamination to a refinery contaminated with hundreds of compounds over every square inch of ground.

Underground petroleum storage tank systems (USTs) have been buried since the early decades of the twentieth century. Not until the mid-1970s did anyone seriously consider the fact that these buried USTs might be leaking gasoline into the environment. The fact that approximately $85 \%$ of all USTs were steel with little or no corrosion protection went unnoticed (Cole, 1994).

If proper remediation measures are not taken, the

*To whom correspondence should be addressed 
organic pollutants released from gasoline spills can lead to surface and groundwater contamination, which can be potentially toxic to biota and humans.

Phenolic compounds, generated by petroleum and petrochemical, coal conversion and phenolproducing industries, are common contaminants in wasterwaters. Thus, it is necessary to identify, characterize and develop effective cleanup or containment methods for these hazardous contaminants.

Organoclays have attracted considerable attention for their use in contaminant treatment (Xu et al., 1997). Due to the isomorphous substitutions in the aluminosilicate layers, natural clay minerals usually have a net negative charge, which is balanced by alkali metal and alkaline-earth-metal cations such as $\mathrm{Na}^{+}$and $\mathrm{Ca}^{2+}$. The strong hydration of these inorganic cations creates a hydrophilic environment on the surface and in the interlayer region of natural smectite clay (Souza Santos, 1992). The substitution of $\mathrm{Na}^{+}$or $\mathrm{Ca}^{2+}$ by quaternary ammonium cations of the form $\left[\left(\mathrm{CH}_{3}\right)_{3} \mathrm{NR}\right]^{+}$or $\left[\left(\mathrm{CH}_{3}\right)_{2} \mathrm{NRR}\right]^{+}$at the exchangeable sites of natural clays results in organoclay derivatives with organophilic properties that can act as sorbent contaminant hydrocarbons (Büchler, 1986a, 1986b; Jaynes and Boyd, 1990; Xu and Boyd, 1995). Organoclays are effective sorbents for a variety of aqueous organic compounds, including many common groundwater contaminants (Boyd, et al., 1988a, 1988b; Lee et al., 1989, 1990; Sharmasarkar et al., 2000).

The use of organoclays in conjunction with conventional bentonite clay provides a barrier with the combined ability to act as a sealant and to effectively adsorb and retain dissolved organic contaminants. This type of composite liner provides an additional barrier to the escape of chemicals from storage tanks and landfills and represents a fundamental improvement in liner technology (Jaynes and Boyd, 1990).

Organoclays formed with quaternary ammonium salts such as trimethylphenylammonium (TMPA) or hexadecyltrimethylammonium (HDTMA) from smectite were more effective sorbents for phenol and chlorophenols than unmodified smectite. Sorption of phenol was maximized when TMPA clay was utilized as the sorbent (Jaynes and Boyd, 1990).

Dentel investigated the $\mathrm{pH}$ effect on sorption characteristics of 1,2,4-trichlorobenzene (1,2,4-TCB) by HDTMA-clay. The $\mathrm{pH}$ effect on 1,2,4-TCB uptake by HDTMA-clay is not very significant, perhaps because properties of HDTMA-clay are not pH dependent (Dentel, 1996).

In countries like Brazil, where known deposits of natural bentonites with a high capacity for swelling do not exist, the usual practice is to treat nonswelling bentonites with sodium carbonate in order to exchange the interlayer cations for sodium and obtain swelling clays. The industrial cation exchange procedure is described by Dematte (1980). A new laboratory procedure for this type of cation exchange is described by Valenzuela-Díaz (1996, 2001).

As organic compounds are considered priority pollutants since they are harmful to organisms, three materials were evaluated as sorbents of organic compounds. The materials are an ARO and two organoclays (ABDMA-SVC and ABDMA-SWy). The organoclays were prepared using a bentonite from the Brazilian state of Paraíba (SVC), sodium exchanged in the laboratory and the Wyoming bentonite (SWy) with a Brazilian quaternary ammonium salt. The salt used was alkyl benzyl dimethyl ammonium chloride (ABDMA). We used this salt because it had the dodecyl and the benzyl groups, which are used to make organoclays (Jaynes and Vance, 1996; Sheng et al., 1997; Sheng and Boyd, 1998; Lo et al., 1998; Ceyhan et al., 1999; Sharmasarkar et al., 2000). The $\mathrm{pH}$ effect on phenol uptake by ABDMA-SVC, ABDMA-SWy and ARO was not investigated.

\section{MATERIALS AND METHODS}

The smectite from Wyoming (SWy) was purchased from Sigma Chemicals. The smectite clays from the Brazilian state of Paraíba (SVC)with the sodium exchanged in the laboratory were prepared in the manner previously described by Valenzuela Díaz et al. (2001). The salt was obtained from Clariant Divison Surfactants. The clays had $\mathrm{Na}^{+}$exchangeable cations and a cation-exchange capacity (CEC) of $\sim 100 \mathrm{cmol} / \mathrm{kg}$ (centimoles of charge $\mathrm{kg}^{-1}$ ). The Na clays were dispersed by mixing with water and then clays were left to settle overnight. The clay supernatant was removed and mixed with an aqueous solution of ABDMA chloride salt in the amount of 100 meq ABDMA per $100 \mathrm{~g}$ of the clays and stirred for 20 minutes. The ABDMAsmectite complexes were vacuum filtered and washed with distilled water until free of $\mathrm{Cl}^{-}$and stored at room temperature.

The ARO was prepared at Department of Mettalurgical and Materials Engineering, Polytechnic School, University of São Paulo, São Paulo, Brazil, (PMT/EPUSP).

The diesel, gas and kerosene were obtained from Petróleo Brasileiro S. A. (Petrobrás).

Varsol is a commercial mixture of lowmolecular-weight aliphatic hydrocarbons. 
Basal spacings were determined by X-ray diffraction (XRD) analysis. X-ray diffraction patterns were recorded using $\mathrm{CuK} \alpha$ radiation $(\lambda=$ $1.5416 \AA$ ) and a Philips XPERT-MPD X-ray diffractometer in steps of $0.02^{\circ} 2 \theta$ at $1.0 \mathrm{~s} / \mathrm{step}$.

Adsorption isotherms were determined using the batch equilibration technique. The initial concentrations of phenol were prepared in the range of 200 to $800 \mathrm{mg} / \mathrm{L}$. Glass tubes $(35 \mathrm{~mL})$ containing $500 \mathrm{mg}$ of organoclays and $25 \mathrm{~mL}$ of phenol aqueous solutions were closed and mixed. Every batch stood for 24 hours at $33{ }^{\circ} \mathrm{C}$. Preliminary kinetic work indicated that sorption equilibrium was reached in less than $20 \mathrm{hr}$. After reaching equilibrium, the aqueous phase was separated by centrifugation at $3000 \mathrm{rpm}$ for $60 \mathrm{~min}$ at room temperature using a BE-4004 type BIO-ENG. A $10 \mathrm{~mL}$ portion of the supernatant was analyzed by the total organic carbon method (TOC) with a TOC-5000 A type Shimadzu in order to measure concentration of phenol equilibrium. The amounts of phenol adsorbed were calculated by the differences between the initial and equilibrium concentrations. Isotherms were obtained by plotting the amounts adsorbed against the equilibrium concentration in solution. All experiments were carried out in duplicate and each point on the isotherm is the average of two experiments.

The absorption of organic compounds served as an ASTM D 281-95 base. All experiments were carried out in duplicate.

The swelling capacity of organophilic clays in toluene, diesel, kerosene, gas and Varsol, was measured, as described previously by Valenzuela Díaz (2001).

\section{RESULTS AND DISCUSSION}

\section{Swelling}

Table 1 shows the swelling of the organoclays. Intermediate values (between 6 to $8 \mathrm{~mL} / \mathrm{g}$ ) were observed for the swelling in toluene and gas, attesting the organophilicity of the clays.

The organoclays had low (below $5 \mathrm{~mL} / \mathrm{g}$ ) or intermediate values for (between 6 to $8 \mathrm{~mL} / \mathrm{g}$ ) swelling in organic compounds. The ABDMA-SVC had low values for swelling in diesel (without mixing) and intermediate values for swelling in diesel with mixing, in gas with and without mixing and in toluene without mixing. The ABDMA-SVC had high valus for swelling in toluene with mixing. The ABDMA-SWy had low swelling in diesel and in gas both with and without mixing and middle swelling in toluene with and without mixing. All the organoclays had swelling below $3 \mathrm{~mL} / \mathrm{g}$ in Varsol and kerosene.

Table 1: Swelling of organoclays $(\mathrm{mL} / \mathrm{g})$.

\begin{tabular}{|c|c|c|c|}
\hline \multirow{2}{*}{ Organoclays } & \multicolumn{3}{|c|}{ Freundlich } \\
\cline { 2 - 4 } & $\mathbf{n}_{\mathbf{f}}$ & $\mathbf{K}_{\mathbf{f}}(\mathbf{L} / \mathbf{m g})$ & $\mathbf{R}_{\mathbf{f}}^{\mathbf{2}}$ \\
\hline ABDMA-SWy & 1.5260 & 1.2893 & 0.9472 \\
ABDMA-SVC & 1.6152 & 1.0002 & 0.9924 \\
ARO & 2.5529 & 0.5121 & 0.9457 \\
\hline
\end{tabular}

\section{Infrared Curves}

Figure 1 shows the infrared curves for ABDMASVC and ABDMA-SWy. The infrared curves showed the groups $\mathrm{NH}, \mathrm{CH}_{3}$ and $\mathrm{CH}_{2}$, indicating that the cationic quaternary ammonium molecules were intercalated between the clay mineral layers.

\section{X-Ray Diffraction Analysis}

Figure 2 shows the interlayer spacings of the ABDMA-SVC and ABDMA-SWy. All the organoclays were pretreatedt at $60^{\circ} \mathrm{C}, 110^{\circ} \mathrm{C}$ and $350^{\circ} \mathrm{C}$. The X-ray diffraction basal spacings $\left(\mathrm{d}_{001}\right)$ of the ABDMA-SVC and ABDMA-SWy were between 12.60 and $22.15 \AA$. The basal spacings of the ABDMA-SVC were slightly larger than those of the ABDMA-SWy. The basal spacings of the natural clays were approximately $12 \AA$. The X-ray diffraction analysis of the organoclays showed that the interlayer basal spacing of the natural clays was low in comparison to that of the organoclays. The structure of the organoclays did not collapse at $350^{\circ} \mathrm{C}$. 


\section{Absorption}

The absorption of organic compounds served as an ASTM D 281-95 base. Table 2 shows the results for ABDMA-SVC, ABDMA-SWy and ARO. The order of ABDMA-SWy absorption was gas $>$ toluene $>$ Varsol $>$ diesel $>$ kerosene.

The order of ABDMA-SVC absorption was gas $>$ toluene $>$ kerosene $>$ diesel $>$ Varsol. The order of ARO absorption was gas $>$ toluene $>$ diesel $>$ Varsol $>$ kerosene.

The data showed that the ABDMA-SVC absorbed more gas $(32.71 \%)$ and kerosene $(22.54 \%)$ than did the ABDMA-SWy. The ARO absorbed more diesel $(5.95 \%)$ than the ABDMA-SVC and more toluene $(8.47 \%)$ than the ABDMA-SWy.

\section{Sorption of Phenol}

Sorption of phenol (Figure 3) occured in the following order: ABDMA-SVC > ABDMA-SWy > ARO.

The Langmuir and Freundlich models are the most frequently employed models. Banat (2000) used both models to describe the relantionship between the amount of phenol adsorbed and its equilibrium concentration. A comparison of correlation of the data $\left(\mathrm{R}^{2}\right)$ values indicated that the data would better fit with the Freundlich model than the Langmuir equation (Banat, 2000).

In this work the data were fitted to the Freundlich model, resulting in greater correlation of the data $\left(\mathrm{R}^{2}\right)$. The Freundlich equation can be expressed as follows:

$y=K_{f} C_{e}{ }_{f}^{n-1} \quad$ Freundlich equation

where $\mathrm{K}_{\mathrm{f}}\left(\mathrm{L} / \mathrm{mg}\right.$ ) and $\mathrm{n}_{\mathrm{f}}$ (dimensionless) are constants related to sorbate-binding capacity and a conditional index that describes the shape of the isotherm, respectively. The results of fitting models to phenol sorption on organoclays are listed in Table 2. The $\mathrm{n}_{\mathrm{f}}$ values were high than 1 for the three organoclays. Freundlich fitting with $\mathrm{n}_{\mathrm{f}}>1$ would indicate conformity of the data to multilayer formation at the adsorbent surfaces. This observation could also be attributed to the molecular interactions between the sorbate species and subsequent aggregation in the pattern of the surface monolayer. These mechanistic paths could be possible attributes of the conformity of our data with the Freundlich fitting. The $n_{f}$ values that are high than 1 represent sorption results having convex curvatures (Sharmasarkar et al., 2000). Isotherms for ABDMASVC, ABDMA-SWy and ARO followed a convex up pattern. Banat et al. (2000) used natural bentonite to adsorb phenol. He concluded that its adsorptive capacity was limited (on an order of magnitude of 1 $\mathrm{mg} / \mathrm{g}$ ).

Validation of the models for adsorption of phenol by organoclays was confirmed by testing the $\mathrm{R}^{2}$ (correlation coefficient).

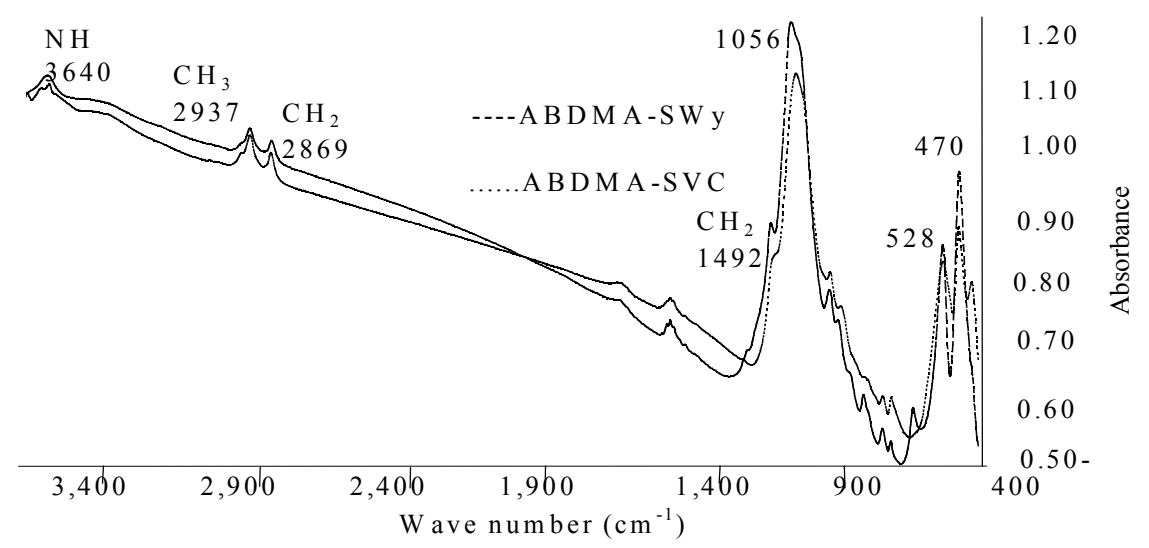

Figure 1: Infrared curves. 

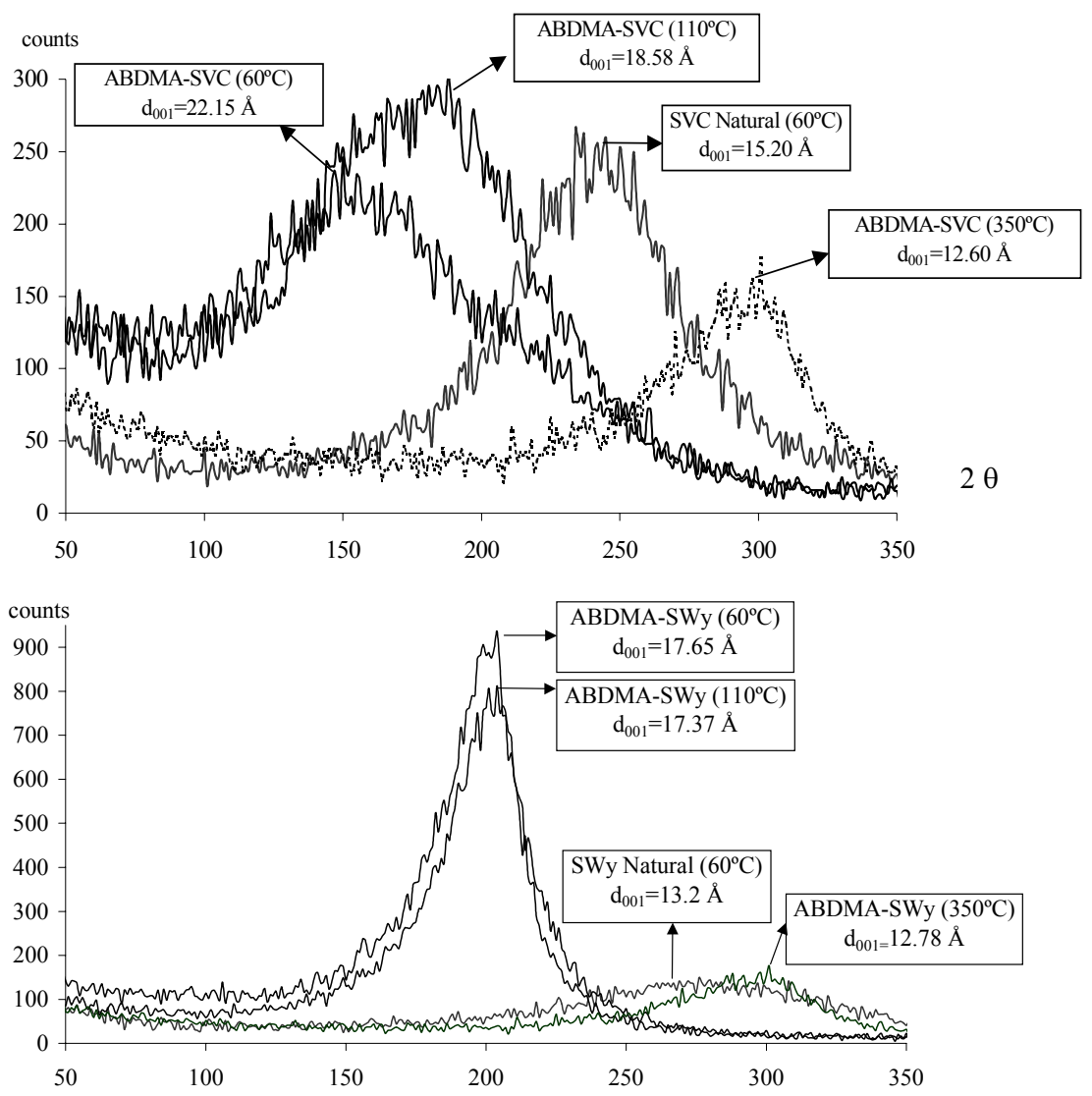

ABDMA-SVC= alkyl benzyl dimethyl ammonium. $\mathrm{SWy}=\mathrm{Wyoming}$ bentonite.

$\mathrm{SVC}=$ bentonite from the Brazilian state of Paraíba. d001=basal spacing.

Figure 2: X-ray diffraction curves.

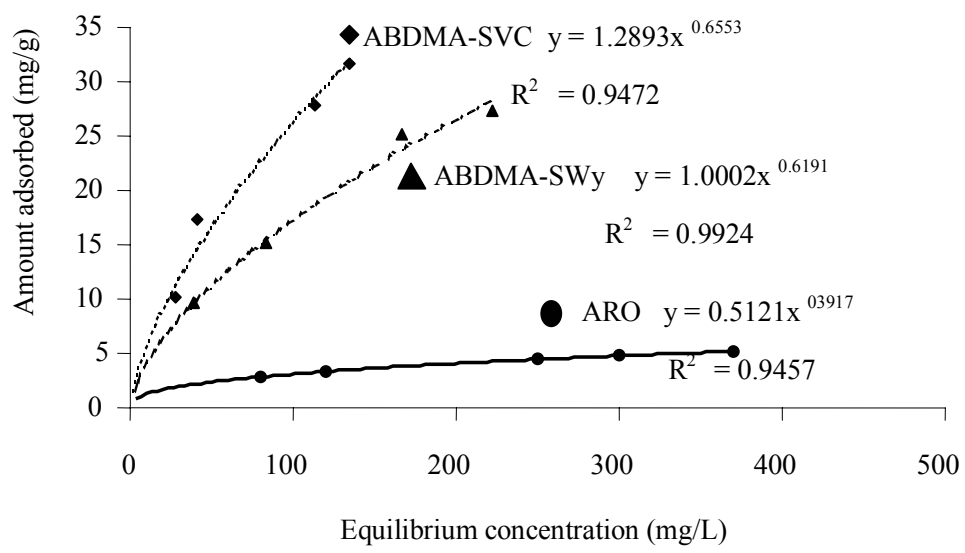

ABDMA= alkyl benzyl dimethyl ammonium.

SWy=Wyoming bentonite.

$\mathrm{SVC}=$ bentonite from the Brazilian state of Paraíba.

$\mathrm{ARO}=\mathrm{coal} /$ mineral complex.

Figure 3: Adsorption isotherms and Freundlich equation. 
Table 2: Absorption (g organic compound/g material).

\begin{tabular}{|c|c|c|c|c|c|c|}
\hline \multirow{2}{*}{ Organoclays } & \multicolumn{3}{|c|}{ Swelling without mixing (mL/g) } & \multicolumn{3}{c|}{ Swelling with mixing (mL/g) } \\
\cline { 2 - 7 } & diesel & gas & toluene & diesel & gas & toluene \\
\hline ABDMA-SWy & 3 & 3 & 6 & 3.5 & 4 & 8 \\
ABDMA-SVC & 4 & 6 & 8 & 6.5 & 6 & 9 \\
\hline
\end{tabular}

Table 3: Model parameters for phenol adsorption by organoclays.

\begin{tabular}{|c|c|c|c|c|c|}
\hline Organoclays & diesel & gas & kerosene & Varsol & toluene \\
\hline ABDMA-SWy & 0.85 & 1.44 & 0.79 & 0.93 & 1.08 \\
ABDMA-SVC & 0.79 & 2.14 & 1.02 & 0.72 & 1.47 \\
ARO & 0.84 & 1.38 & 0.76 & 0.78 & 1.18 \\
\hline
\end{tabular}

ABDMA =alkyl benzyl dimethyl ammonium

$\mathrm{SWy}=\mathrm{Wyoming}$ bentonite.

$\mathrm{SVC}=$ bentonite from the Brazilian state of Paraíba.

$\mathrm{ARO}=\mathrm{coal} /$ mineral complex.

\section{CONCLUSIONS}

The infrared curves (Figure 1) showed groups $\mathrm{NH}, \mathrm{CH}_{2}$ and $\mathrm{CH}_{3}$. The $\mathrm{X}$-ray diffraction basal spacings $\left(\mathrm{d}_{001}\right)$ of the ABDMA-SVC was $22.15 \AA$ and ABDMA-SWy was $17.65 \AA$ at $60^{\circ} \mathrm{C}$. The basal spacings of the natural clays are approximately $12 \AA$ at $60^{\circ} \mathrm{C}$. These facts indicate that the cationic quaternary ammonium molecules became intercalated between the clay mineral layers.

The ABDMA-SVC and ABDMA-SWy adsorption curves for phenol indicate that these organoclays were effective in adsorbing the phenol and can be used as liners and waste disposal reservoirs. The Freundlich isotherms were found to be applicable for the adsorption equilibrium data.

The ABDMA-SVC and ABDMA-SWy data for diesel, gas, kerosene, toluene and Varsol suggests that these organoclays can be utilized more effectively as liners around gasoline storage tanks and waste disposal reservoirs for the purpose of hydrocarbon-containment and controlling pollution from petroleum-contaminated waters.

The data showed that the Brazilian clay is the most efficient of the three materials studied.

\section{ACKNOWLEDGMENTS}

We are grateful to the Brazilian Research Council and the Brazilian Ministry of Education for their financial support and for the purchase of equipment.

\section{REFERENCES}

Banat, F.A., AL-Bashir, B., AL-Asheb, S. and Hayajneh, O., Adsorption of Phenol by Bentonite. Environmental Pollution, vol. 107, no. 3, pp. 391-398, 2000.

Boyd, S.A., Mortland, M.M. and Chiou, C.T., Sorption Characteristics of Organic Compounds on Hexadecyltrimethylammoniun-Smectite. Soil Science Society American Journal, vol. 52, no. 3, pp. 652-657, 1988a.

Boyd, S.A., Sun, S., Lee, J.F. and Mortland, M.M., Pentachlorophenol Sorption by Organoclays. Clays and Clay Minerals, vol. 36, no. 2, pp. 125130, 1988 b.

Büchler, P.M., Sorption of Vinasse in Organoclays. Brazilian Journal of Chemical Engineering, vol. 9, no.1, pp. 28-31, 1986a (in Portuguese).

Büchler, P.M. and Perry, R., The Use of Clay Liners in the Attenuation of the Organic Load of Vinasse in Developing Countries. In: The International Conference on Chemicals in the Environment, Lisbon, 1986. Prooceedings, pp. 715-724. London, Selper, 1986b. .

Ceyhan, O., Guler, H. and Guler, R., Adsorption of Phenol and Methylphenols on Organoclays. Adsorption Science \& Technology, vol. 17, no. 6, pp. 469-477, 1999.

Cole, G.M., Assessment and Remediation of Petroleum Contaminated Sites. $1^{\text {st. }}$ ed. Boca Raton, Florida, CRC Press, Inc, 1994.

Dematte, C.L., Bentonite: Processing and Use in Brazil. Ceramics, vol. 26, p. 353, 1980. 
Dentel, S.K., Use of organoclay Adsorbent Materials for Groundwater Treatment Applications. http://bluehen.ags.udel.edu/dewrc/dwrc.report3.ht m., 1996.

Jaynes, W.F. and Boyd, S.A., Trimethylphenylamonium -smectite as an Effective Adsorbent of Water Soluble Aromatic Hydrocarbons. Journal of the Air Waste Management Association, vol. 40, no. 12, pp. 1649-1653, 1990.

Jaynes, W.F. and Vance, G.F., BTEX Sorption by Organo-clays: Cosorptive Enhancement and Equivalence of Interlayer Complexes. Soil Science American Journal, vol. 60, no. 6, pp. 1742-1749, 1996.

Lee, J.-F., Mortland, M.M., Boyd, S.A and Chiou, C.T., Shape Selective Adsorption of Aromatic Compounds from Water by Tetramethylammonium smectite. Journal of the Chemical Society Faraday Transactions 1, vol. 85, no. 9, pp. 29532962, 1989.

Lee, J.-F., Mortland, M.M., Chiou, C.T., Kile, D.E. and Boyd, S.A., Adsorption of Benzene, Toluene, and Xylene by Two Tetramethylammonium smectites Having Different Charge Densities. Clays and Clay Minerals, vol. 38, no. 2, pp. 113120, 1990.

Lo, I.M.-C., Lee, S.C.-H. and Mak, R.K.-M., Sorption of Nonpolar and Polar Organics on Dicetyldimethylammonium-Bentonite. Waste
Management \& Research, vol. 16, no. 2, pp. 129138, 1998.

Sharmasarkar, S., Jaynes, W.F. and Vance, G.F., BTEX Sorption by Montmorillonite Organoclays: TMPA, ADAM, HDTMA. Water Air and Soil Pollution, vol. 119, no. 1-4, pp. 257-273, 2000.

Sheng, G.Y., Xu, S.H. and Boyd, S.A., Surface Heterogeneity of Trimethylphenylammoniumsmectite as Revealed by Adsorption of Aromatic Hydrocarbons from Water. Clays and Clay Minerals, vol. 45, no. 5, pp. 659-669, 1997.

Sheng, G.Y. and Boyd, S.A., Relation of Water and Neutral Organic Compounds in the Interlayers of Mixed Ca/Trimethylphenylammonium-Smectites. Clays and Clay Minerals, vol. 46, no. 1, pp.10-17, 1998.

Souza Santos, P., Science and Technology of Clays.

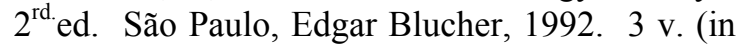
Portuguese).

Valenzuela Díaz, F.R. Preparation of Organophilic Clays from Brazilian Smectitic Clay. Key Engineering Materials, vol. 189-191, pp. 203207, 2001.

$\mathrm{Xu}$, S. and Boyd, S.A., Cationic Surfactant Sorption to a Vermiculitic Subsoil Via Hydrophobic Bonding. Environmental Science \& Technology, vol 29, no. 2, pp. 312-320, 1995.

$\mathrm{Xu}$, S., Sheng, G. and Boyd, S.A., Advances in Agronomy, vol. 59, no. 29, 1997. 